\title{
Práticas educativas bibliotecárias de formação de leitor
}

\author{
Librarian educational practices for reader's formation
}

\author{
Juliana Alves Moreira \\ Mestranda em Ciência da Informação pela Escola de Ciência da Informação da Universidade Federal de Minas \\ Gerais - UFMG. \\ Bibliotecária da Rede Municipal de Educação de Belo Horizonte - MG, Brasil \\ E-mail: juliana.jamore@gmail.com
}

Adriana Bogliolo Sirihal Duarte
Doutora em Ciência da Informação pela Universidade Federal de Minas Gerais - UFMG.
Professora do Departamento de Teoria e Gestão da Informação da Escola de Ciência da Informação da UFMG.
E-mail: bogliolo@eci.ufmg.br

\section{Resumo}

Apresenta resultado de levantamento, feito na base de Literatura Brasileira em Biblioteca Escolar - LIBES do Grupo de Estudos em Biblioteca Escolar - GEBE da ECI/UFMG, sobre as práticas de promoção de leitura empreendidas nas bibliotecas escolares, especificamente, por bibliotecários, profissionais estes muito recentemente incluídos no contexto escolar e que convivem com a necessidade de mediar informação e leitura. Apresenta e analisa: período das publicações, autoria, a localidade dos autores e os veículos de publicação utilizados. Constata diferentes acepções de conceitos, terminologias e objetivos do trabalho com a leitura, refletidos, por exemplo, na inconsistência terminológica entre promover o hábito ou o gosto pela leitura. A partir do suporte oferecido por este mapeamento sobre como as práticas de promoção de leitura foram concebidas e realizadas ao longo do tempo, reflete sobre a importância do papel do bibliotecário como mediador na promoção da leitura e propõe a expressão "práticas educativas bibliotecárias de formação de leitor", sendo essas práticas entendidas como definidoras e estruturantes de uma atuação profissional que congrega necessariamente dimensões político-pedagógicas.

Palavras-chave: Leitura. Formação do Leitor. Bibliotecário. Práticas Educativas.

\begin{abstract}
Presents results of a survey conducted on the data basis called Literatura Brasileira em Biblioteca Escolar LIBES, held by the Brazilian Study Group on School Library - Grupo de Estudos em Biblioteca Escolar - GEBE of Universidade Federal de Minas Gerais. The survey investigated the practices undertaken to promote reading in school libraries specifically by librarians. In Brazil, those professionals were very recently included in the school and live with the need to mediate information and reading. This paper presents and analyzes the time of publication, authorship, the location of the authors and the type of work. It's observed that there are different meanings of concepts, terminology and objectives of the work with reading. This is reflected, for example, in the inconsistency in terminology between promoting the habit of reading and promoting the love of reading. From the support offered by this mapping on the practices of reading promotion, a reflection on the importance of the role of the librarian as mediator in promoting reading is proposed. Finally, the terminology "librarian educational practices for reader's formation" is proposed being these practices understood as defining and structuring professional practices that embrace necessarily political-pedagogical dimensions.
\end{abstract}

Keywords: Reading. Reader's formation. Librarian. Educational practices. 


\section{Introdução}

A leitura e sua respectiva promoção constituem, ainda hoje, um problema basilar da educação brasileira seja em função dos níveis elementares de competência que os indivíduos atingiram, ao longo dos anos, ou em razão da ausência/deficiência desses primeiros. Na última década, conforme nos reportam Carvalho e Souza (2012), ele vem ganhando importância nas agendas das instituições públicas, federais, estaduais e municipais através da criação de planos e programas de fomento, entre os quais se destaca o Plano Nacional do Livro e da Leitura - PNLL, iniciado em 2006.

A pesquisa Retratos da Leitura no Brasil, coordenada pelo Instituto Pró-Livro, em sua terceira edição, define como leitores os indivíduos que tenham lido "inteiro ou em partes, pelo menos um livro nos últimos três meses" (IPL, 2012, p. 47). Baseando-se em tal definição, a coleta de dados realizada em 2011 diagnostica que 50\% da população brasileira com cinco anos ou mais é composta de leitores, sendo os outros $50 \%$ não leitores. A mesma pesquisa afirma que entre os estudantes brasileiros $75 \%$ são leitores e $25 \%$ são não leitores, o que equivale a dizer que um quarto dos estudantes brasileiros não leu nenhum livro nos últimos três meses (IPL, 2012, p. 47-50). Esse nível de leitura entre os estudantes brasileiros, tão alardeado na mídia, é vislumbrado, principalmente, através da divulgação dos índices de instrumentos como o Prova Brasil, o ENEM e o Programa Internacional de Avaliação de Alunos - PISA.

Outra constatação, expressa ainda na pesquisa Retratos da leitura, é a de que no Brasil, o problema de promoção da leitura passa, ainda, pela dificuldade de acesso aos materiais de leitura (livros, revistas, jornais, etc.) e de efetivação dos espaços de leitura, explica Cunha (2008), o tem concorrido para confirmar a necessária relação entre leitura e educação e, objetivamente, entre leitura e escola. Minimamente, às escolas cabe o provimento do acesso ao livro e, de modo particular, o incentivo à leitura no sentido de educação como formação e informação dos indivíduos.

Nessa perspectiva, o trabalho com a leitura na escola, viabilizado pelos seus primeiros e referenciais agentes - os professores -, foi pautado, cita Magnani (1989), pela utilização de práticas de promoção de leitura específicas e ancoradas nos livros didáticos como um primeiro contato e, depois, com os livros paradidáticos, além de livros de literatura clássica que compunham o acervo de classe, em sua maioria doados por editoras. 
Apesar de ter havido uma progressiva oferta de materiais de leitura na sala de aula e da evolução do objetivo de ensinar leitura na escola, Galvão e Batista (1998) consideram que, essa suposta evolução, teria ficado mais nos discursos sobre a leitura do que na prática, o que se agrava pela ausência de políticas governamentais que efetivem projetos de valorização da leitura e de implementação de bibliotecas. Assim, muitas iniciativas em torno dos livros e da leitura acabavam (e acabam) acontecendo por empreendimentos individuais de pequenos grupos, principalmente nas escolas.

Apenas em meados do século XIX, revela Kolokathis (2008), é que foram criadas as primeiras bibliotecas nas escolas públicas brasileiras, que se cristalizaram como espaço alternativo à sala de aula para o acesso, que se revelou mais tarde estar maciçamente circunscrito a complementação das atividades de sala de aula e suporte para a pesquisa, uma vez que os professores

parecem colocar a biblioteca e os bibliotecários na posição de subalternos ou
apêndices do processo educativo, devendo, por isso mesmo, cumprir e nunca
questionar (ou ao menos enriquecer) os procedimentos oriundos do contexto da
escola (SILVA, 1995, p. 68).

Como se poderá observar, a promoção da leitura via biblioteca escolar em relação à promoção via sala de aula é recente e, mais recente ainda é a presença do bibliotecário atuando nesse campo porque, da mesma maneira que a criação de bibliotecas no ambiente escolar público não se deu de modo automático, os agentes que ali passaram a atuar num primeiro momento e, em muitos casos, ainda atualmente, foram os professores e não os bibliotecários. Desse modo, as práticas (atividades, ações e projetos) de promoção de leitura que foram desenvolvidas ao longo dos anos, estendendo-se ao ambiente da biblioteca escolar tinham, igualmente àquelas propostas em sala de aula, uma orientação específica, própria do trabalho docente, não explorando, quase nunca, as potencialidades do acervo e serviços de biblioteca.

A discussão sobre a leitura e a sua promoção na escola permanece contemporânea, bem como persiste a dificuldade em se resolver o problema do baixo índice de leitura entre os estudantes, evidenciando que as práticas de promoção de leitura, em sua concepção e/ou realização, não se efetivaram positivamente, quer na sala de aula, quer no dito apêndice - a biblioteca escolar. Mesmo com a inclusão do profissional bibliotecário na biblioteca escolar e no já conturbado cenário educacional brasileiro, a questão da leitura e das práticas promoção da leitura nesse espaço ainda não se resolveu. 
O que pode ser constatado é que a tônica das discussões do trabalho com/para a leitura na biblioteca, pelos bibliotecários, oscila, em grande medida, do simplório e relegado papel de suporte das atividades de sala de aula, e/ou a organização e difusão tradicionais da informação, para a proposição e incremento das habilidades do denominado letramento informacional (influência estadunidense que a partir da década de 1980 passou a inspirar os profissionais). Educar para a pesquisa ou preparar o usuário para que ele possua competência ou letramento informacional significa, segundo Carvalho e Souza (2012), que além das habilidades de localizar e recuperar a informação, o bibliotecário deva assumir também o papel de educador que, envolvido com seus usuários, ensina a aprender a aprender. Contudo, como nos alerta Macedo (2007), a competência informacional, entendida como a capacitação para o competente uso da informação, é etapa posterior à iniciação implícita do usuário ao ato de ler criticamente e às formas do aprender a aprender fazendo. Nesse estágio inicial, deveria estar, mas não está, o bibliotecário como mediador da leitura e colaborador do professor no processo de formação intelectual de crianças e jovens (CARVALHO e SOUZA, 2012, p. 200).

Caroline Stein (2002) apresenta o conceito de letramento a partir de um espectro que parte do letramento alfabético (capacidade de codificar nomes), passando pelo letramento funcional (capacidade de ler e escrever), letramento social (capacidade de comunicar-se em um contexto cultural), letramento informacional (capacidade de localizar, avaliar e usar criticamente a informação) e letramento digital (aplicação do letramento informacional no ambiente digital). A autora deixa, portanto, evidente que não há possibilidade de se atingir o letramento informacional sem se alcançar o letramento funcional, ou seja, sem ser leitor. A leitura é um processo que Barthes e Compagnon (1987) descrevem como o reconhecimento a desconstrução do texto, e a compreensão - a construção de um outro texto (o do próprio leitor), que toma em consideração o livro e o faz existir. Carvalho (2012) nos lembra que para atuar de maneira eficiente nesse processo que além de complexo é também basilar para viabilizar a exploração de outras competências como a informacional, não basta simplesmente mediá-lo através de atividades pontuais, pois

A força da leitura nasce da adesão dos sujeitos, não ao sentido prévio que toda escrita guarda, mas ao processo significante em que cada leitor é convocado a se inserir para fazer interpretação/criação (YUNES, 2002, p. 54).

Desse modo, o resgate das práticas de promoção de leitura, especialmente as realizadas na biblioteca escolar pelo bibliotecário, e a reflexão sobre como foram estruturadas e devem se estruturar torna-se imperativo. Acreditamos, inclusive, que se situa aí a lacuna no 
que diz respeito à própria delimitação e valorização da biblioteca e do bibliotecário dentro da educação, da escola e dos processos educativos fundamentados na leitura, já que, como sentencia Almeida Júnior (2007), a mediação da leitura faz parte da mediação da informação e, enquanto o bibliotecário se restringir apenas a essa última, não será possível lograr êxito.

Assim, visando explorar, caracterizar e refletir mais detidamente sobre as práticas (atividades, ações e projetos) de promoção de leitura, ou seja, sobre a viabilização do trabalho mediativo efetivado pelos bibliotecários, nos propusemos a realizar um levantamento das práticas de promoção de leitura na biblioteca escolar para que, localizando e caracterizando quais vem sendo essas práticas, pudéssemos definir o que passaremos a denominar de "práticas educativas bibliotecárias de formação de leitor".

Esse levantamento foi realizado, no período de março a junho de 2013, na base Literatura Brasileira em biblioteca Escolar - LIBES, mantida pelo Grupo de Estudos em Biblioteca Escolar - GEBE, da Escola de Ciência da Informação da Universidade Federal de Minas Gerais - ECI/UFMG. A LIBES é uma base de dados que reúne referências de documentos sobre biblioteca escolar produzidos no Brasil a partir da década de 1960. Inclui livros, artigos de periódicos, dissertações, teses e trabalhos apresentados em eventos, a maioria deles presentes no acervo da Biblioteca Etelvina Lima, da Escola de Ciência da Informação da UFMG. ${ }^{1}$ A seleção das referências deu-se a partir da identificação daquelas que continham, como palavras-chave, título e resumo, os termos "leitor" e "leitura". Encontradas as referências, apenas permaneceram na amostra aqueles trabalhos que efetivamente explicitavam sobre práticas de promoção de leitura nas bibliotecas, especialmente por bibliotecários, enumerando-as e explicitando seu funcionamento.

A seguir, apresentamos a compilação dos dados bem como a análise dos resultados.

\footnotetext{
${ }^{1}$ Fonte: http://gebe.eci.ufmg.br/index.php?option=com $\_$content\&view=article\&id=49\&Itemid=40. Acesso em: 20 jun. 2013.
} 


\section{Práticas de promoção de leitura na base LIBES}

Do total de 429 registros disponíveis na base LIBES, foram identificadas apenas 63 referências sobre as práticas de promoção de leitura e destas, não tivemos acesso físico ao documento de 6, após tentativas frustradas de localização nas bibliotecas da UFMG, PUC MINAS, NEWTON PAIVA, UNA, UNI e UEMG, somadas a impossibilidade de aquisição, dado o formato não comercial. Restaram e foram consultadas 57 referências, o que em relação ao total significou $10 \%$ dos registros da base LIBES, conforme apresentado no GRÁFICO. 1.

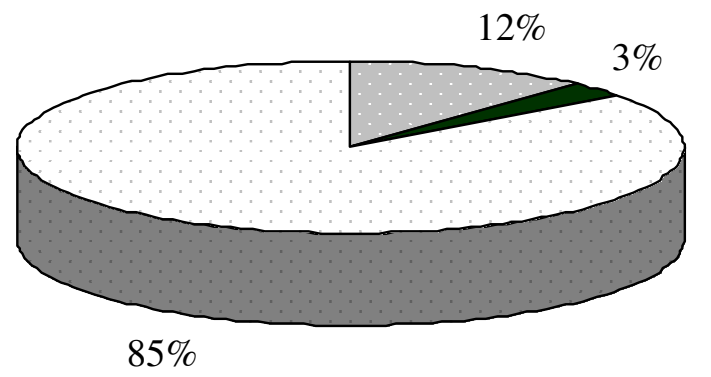

$\square$ Práticas de Leitura Localizados

— Práticas de Leitura Não-Localizados

$\square$ Demais Registros LIBES

GRÁFICO 1 - Práticas de promoção de leitura - Quantitativo selecionado x utilizado Fonte: Dados coletados na pesquisa na base LIBES de março a junho/2013

Observa-se que dos 63 registros sobre práticas de promoção de leitura presentes na base LIBES, a análise feita nesse artigo de 57 registros, correspondeu a 90,48\% da amostra selecionada.

\section{Tipos de publicação}

Foram identificados seis tipos de publicação que tratavam da temática das práticas de promoção da leitura, conforme distribuição apresentada no GRÁFICO. 2.

A maior parte das publicações está concentrada nos trabalhos apresentados em eventos sendo dois em eventos científicos e 15 em eventos profissionais, especificamente, o Encontro Nacional de Pesquisa em Ciência da Informação (ENANCIB), o Congresso Brasileiro de 
Biblioteconomia, Documentação e Ciência da Informação (CBBD) e o Seminário Biblioteca Escolar.

Os trabalhos apresentados em eventos científicos acionaram, necessariamente, pressupostos teóricos da educação, biblioteconomia, ciência da informação, linguística, psicologia, sociologia e outros para tratar acerca das práticas educativas. A discussão estava centrada no tipo de orientação e pressupostos das práticas.

Já os trabalhos apresentados em eventos profissionais, em sua maioria, apenas fizeram um relato de experiência, sem sustentação teórica evidente. A discussão era simultaneamente conduzida por professores e bibliotecários que atuavam nas bibliotecas escolares, mas não se mostraram notórias e identificáveis as diferenças da prática entre um e outro profissional.

O ano de 2005 é o de maior concentração dos trabalhos sobre práticas de promoção de leitura apresentados em eventos, com seis trabalhos tendo sido apresentados num mesmo congresso de biblioteconomia, o CBBD.

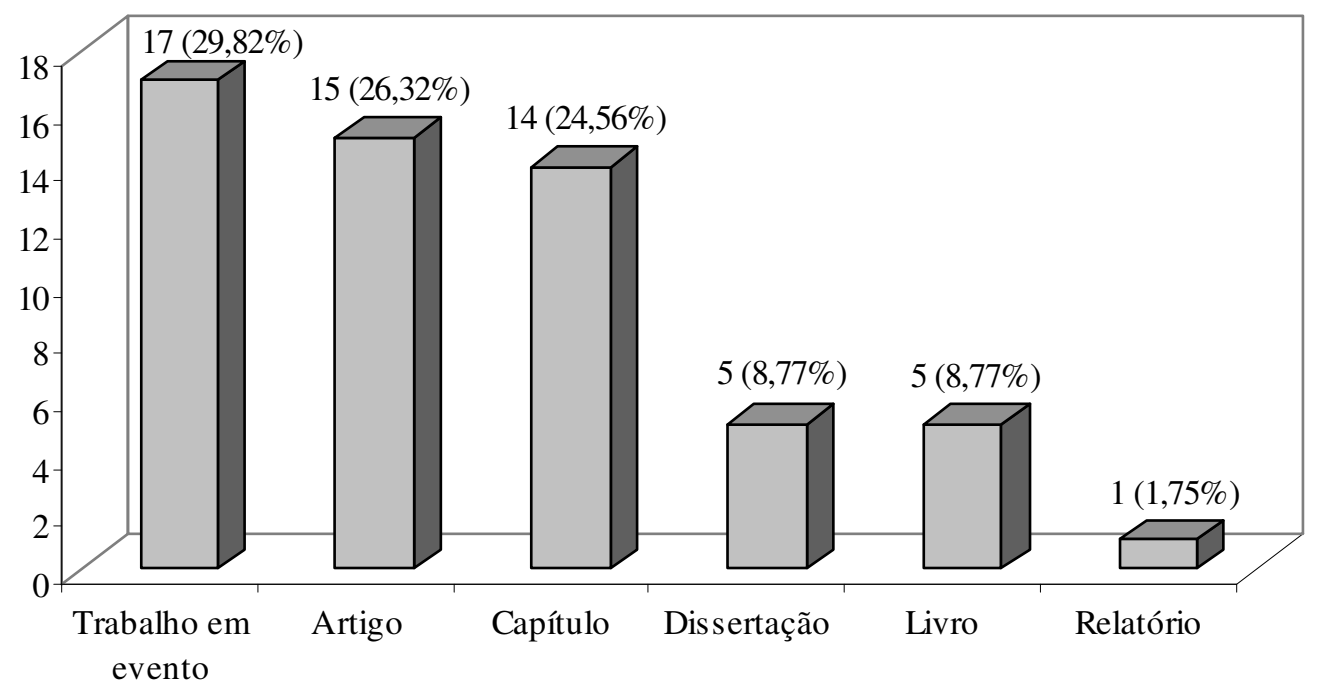

GRÁFICO 2 - Tipos de publicação sobre práticas de promoção da leitura Fonte: Dados coletados na pesquisa na base LIBES de março a junho/2013

Em segundo lugar na concentração das publicações aparecem, empatados, os capítulos de livro e os artigos em periódicos. No estado de São Paulo encontramos a maior concentração dos capítulos de livros. Ressalta-se a presença de dois capítulos de um membro da Associação Americana de Bibliotecários, a ALA.

Quanto à produção dos artigos, tem-se que estes foram publicados em revistas científicas e de profissionais sendo que o estado de Minas Gerais concentrou a maioria deles. 
A produção das dissertações sobre práticas de promoção de leitura identificadas na base LIBES encontra-se assim distribuída: três em Minas Gerais, uma no Rio de Janeiro e uma em São Paulo sendo que todas foram defendidas junto aos programas de pós-graduação em educação.

Os livros publicados são coletâneas de artigos que versam sobre vários aspectos ligados a biblioteca escolar (organização, acervo, pessoal, projetos, etc.) ou sobre a educação brasileira e a promoção da leitura também via biblioteca escolar, sem destaque especial para uma atuação genuína do bibliotecário nesse aspecto; pelo contrário, com grandes ressalvas à sua ineficiência.

O único relatório encontrado era um resumo das principais diretrizes políticas à época - 1985, que deveriam envolver o trabalho de promoção da leitura a partir dos acervos existentes na escola e da formação dos professores. O bibliotecário era relacionado como colaborador do professor nesse processo.

\section{Período das publicações}

O intervalo de tempo para as publicações localizadas na base LIBES que versavam sobre as práticas de leitura é de 1971-2011, com a seguinte distribuição em relação aos tipos de publicações:

\begin{tabular}{c|c|c}
\multicolumn{3}{c}{ QUADRO 1 - Distribuição quantitativa das publicações por tipo e ano } \\
\hline TIPO & ANO & QUANTIDADE \\
\hline Dissertação & $1980,1989,1997,2003,2008$ & $\mathbf{5}$ \\
\hline Artigo & $1973,1986,1987,1991,1994,1996,1998,1999$, & $\mathbf{1 5}$ \\
& $2000,2003,2005,2006,2007(2 x), 2010$ & $\mathbf{1 7}$ \\
\hline $\begin{array}{c}\text { Trabalho em } \\
\text { evento }\end{array}$ & $1995,1998,1999,2000(2 x), 2002(2 x), 2003$, & \\
\hline Livro & $2005(7 x), 2007,2009,2011$ & $\mathbf{5}$ \\
\hline Capítulo & $1986,1995($ red.1986) $2006,2009,2010$ & $\mathbf{1 4}$ \\
\hline Relatório & $1971(2 x), 1983,1989(5 x), 1990,2002(3 x), 2010(2 x)$ & $\mathbf{1}$ \\
\hline Total & & $\mathbf{5 7}$ \\
\hline
\end{tabular}

Fonte: Dados coletados na pesquisa na base LIBES de março a junho/2013 
Segundo os dados dispostos na tabela, não há uma regularidade, sequer anual, para as publicações: no caso das dissertações, o intervalo médio entre uma e outra é 7 anos.

No caso dos artigos, vemos um intervalo grande entre a primeira e a segunda publicação sobre as práticas de leitura (18 anos). No entanto, a partir de 1991, o intervalo médio de ocorrência de artigos sobre o tema é de 3 anos, o que denota a recorrência em se tratar da temática, ainda que seja apenas para divulgá-la.

Quanto aos trabalhos apresentados em eventos, observa-se maior regularidade de ocorrências durante os anos 2000 sendo que em todos os Congressos de Biblioteconomia, Ciência da Informação e Documentação (CBBD, evento bienal) encontramos no mínimo uma publicação relativa às práticas de promoção de leitura.

Finalmente, os capítulos em livros seguem a mesma tendência de publicação das dissertações, com um intervalo médio de 7-8 anos.

O surgimento de publicações sobre as práticas de promoção de leitura, duas em 1971 e uma em 1973, além das seis publicadas na década de 1980, ainda que não encontradas exatamente com este termo, coincidem com o período de efervescência das discussões sobre a promoção da leitura no ambiente da escola. A discussão acerca das práticas de promoção de leitura por bibliotecários pode ser situada, destacam Bari e Vergueiro (2008), em primeiro lugar, na reflexão e alteração do papel/função da biblioteca escolar oriunda da própria mudança na concepção de ensino que, no Brasil, foi consolidar-se no final de 1970, após as pesquisas de Paulo Freire que eram opostas às políticas educacionais e culturais do período de ditadura militar.

Isto significou uma outra conotação para a leitura, menos passiva, assim como a educação deveria ser, que ancorada nos princípios de democratização do acesso como serviço social básico, teve na ampliação dos acervos, a sua maior expressão. A mediação desses acervos, pelas práticas instituídas na escola, foi posteriormente problematizada e a prática dos bibliotecários, apenas muito mais recente e timidamente. 


\section{Origem das publicações}

Os 57 trabalhos analisados foram escritos por 53 autores distintos. A escolha de se fazer a análise da origem do autor e não da publicação justifica-se pela necessidade de situar as regiões e pessoas envolvidas com as práticas educativas, ainda que essas experiências/iniciativas tenham sido publicadas fora de seus estados de origem. Desse modo seria possível identificar o vínculo de cada região com a temática e traçar um panorama de como foram compostas e estruturadas as concepções sobre as práticas de leitura num modelo de escola brasileira, ao qual os autores estão atrelados, e que se sabe não ser padrão em todo o país.

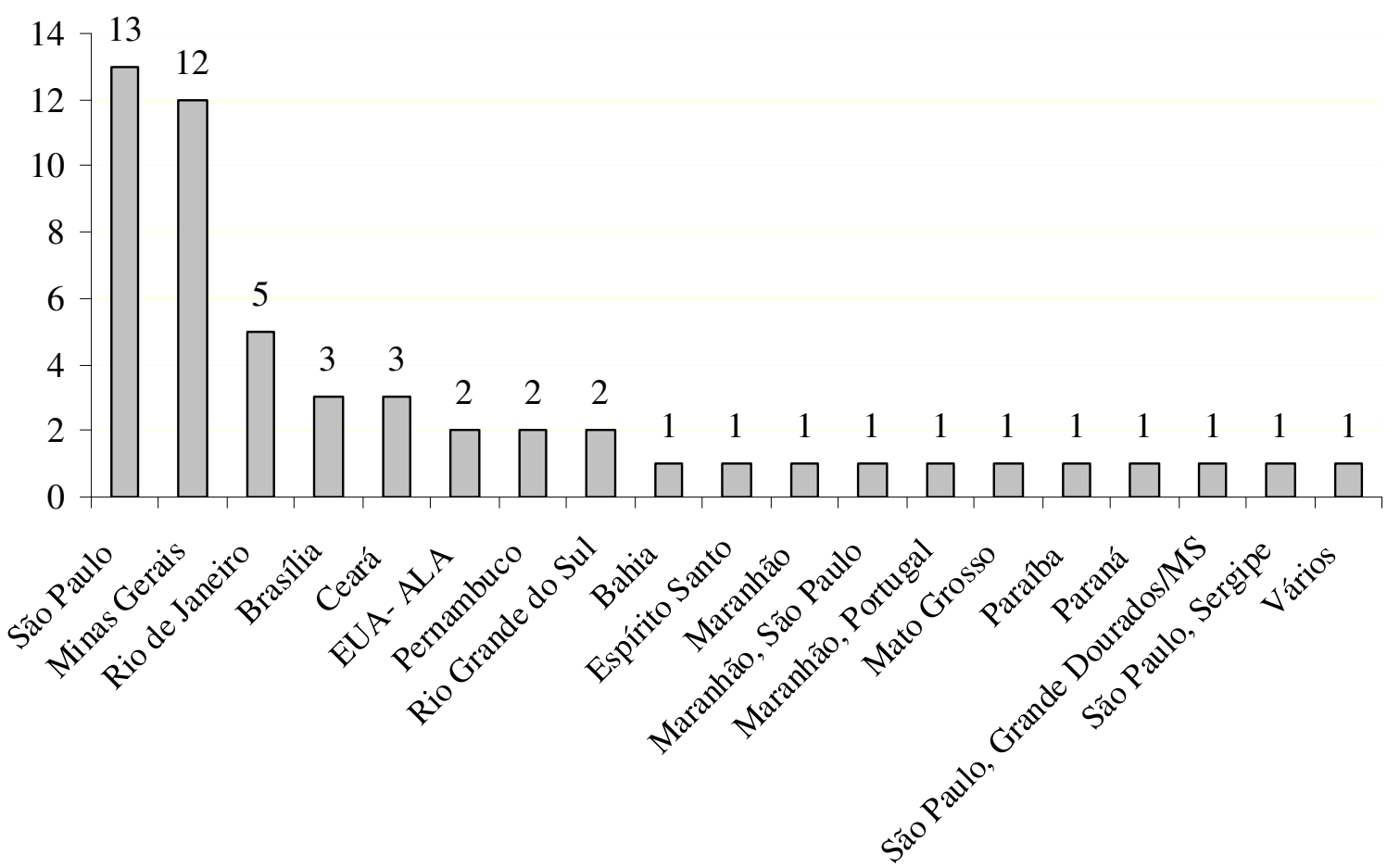

GRÁFICO 3 - Distribuição quantitativa das publicações por local de origem dos autores Fonte: Dados coletados na pesquisa na base LIBES de março a junho/2013

O eixo Sudeste é o que mais se dedicou à produção da temática das práticas de promoção de leitura. Excluindo-se a produção dos estados de São Paulo, Minas Gerais e Rio de Janeiro, pode-se dizer que a distribuição dos trabalhos sobre práticas de produção de leitura, de modo geral, está bem equilibrada, entre os demais estados brasileiros, com algumas contribuições internacionais entre as publicações localizadas na base LIBES (EUA e Portugal). 
Alguns trabalhos, em co-autoria, apresentam mais de uma localidade. No caso de um deles, um livro, não foi possível identificar as localidades de todos os autores, daí o uso da expressão "vários".

Embora se devendo ao estado de Minas Gerais o pioneirismo das discussões brasileiras acerca das práticas de promoção de leitura - o que ocorreu em 1973, no estado de São Paulo está concentrada a maior parte dos trabalhos lidos, um total de 16 (3 em co-autoria) contra 12 dos de Minas Gerais.

Chama a atenção o fato de $15 \%$ dos autores serem da região nordeste, diluídos entre os estados que a compõem (3 CE, 2 PE, 1 BA, 1 PB e 1 SE) uma vez que, ainda que seja de conhecimento que os impactos das mudanças educacionais, sociais, políticas, culturais etc., não sejam os mesmos para todas as regiões do Brasil, a discussão sobre as práticas de promoção de leitura no ambiente da biblioteca faz-se presente nesta região de forma bastante significativa.

\section{Autoria das publicações}

Muito embora estivemos mapeando as práticas de promoção de leitura na biblioteca, não foi sempre o profissional bibliotecário que registrou sua análise. Destacamos que esta foi compartilhada entre professores da educação básica/fundamental e do ensino superior, embora não tenhamos encontrado contribuições de professores do ensino médio.

O GRÁFICO. 4 a seguir apresenta a ocupação dos autores dos trabalhos analisados. 


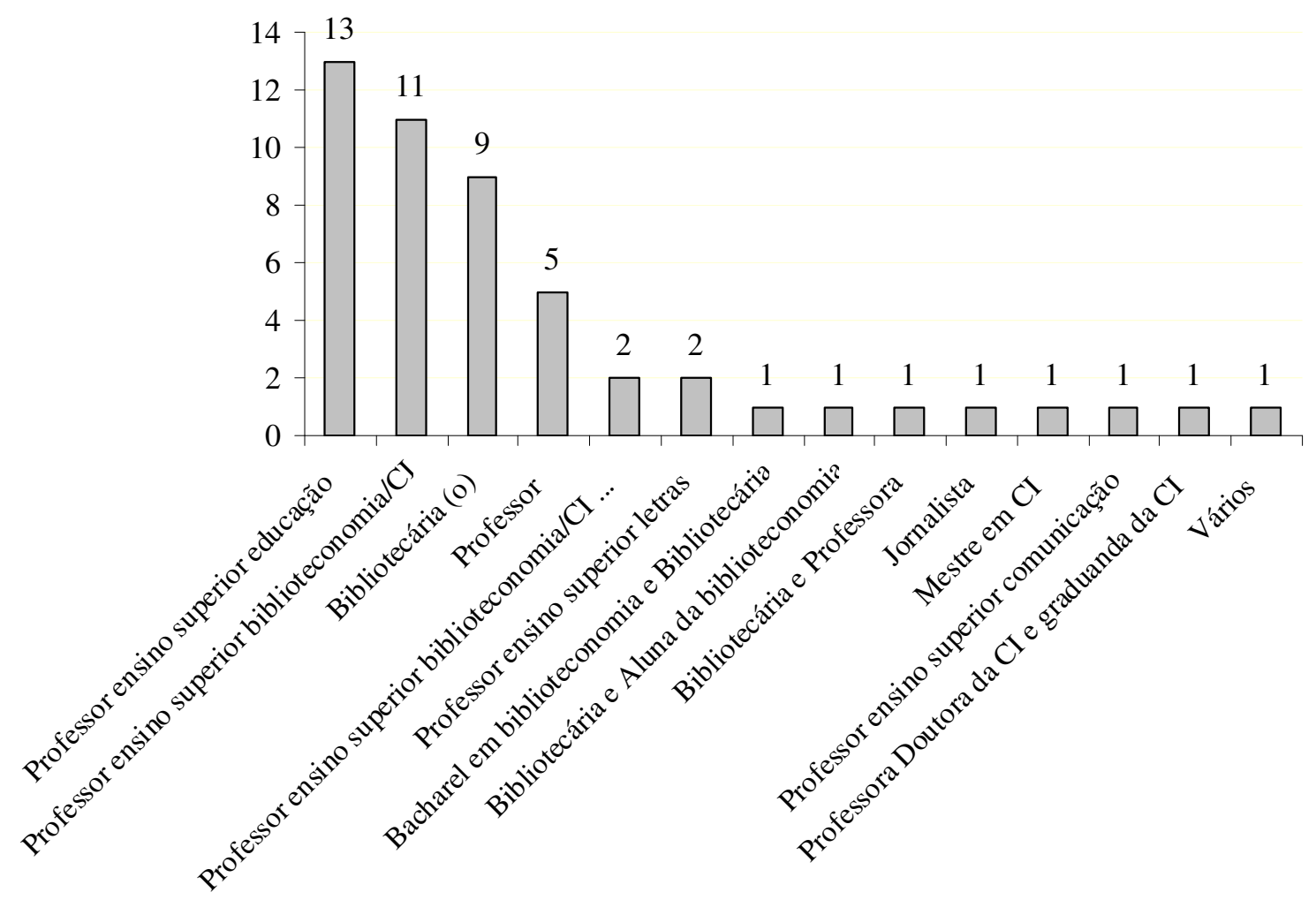

GRÁFICO 4 - Distribuição dos autores sobre práticas de promoção de leitura por ocupação Fonte: Dados coletados na pesquisa na base LIBES de março a junho/2013

Deste universo de referências efetivamente consultadas, constata-se que a menção às práticas de promoção de leitura nas bibliotecas, por bibliotecários, não possui destacada expressividade nas reflexões que envolvem biblioteca escolar e promoção da leitura.

Encontramos com maior frequência a promoção de atividades pelos professores e, mesmo se executadas no ambiente das bibliotecas, eram apresentadas como simples transposição do que já era realizado em sala de aula ou apenas como atividades complementar.

Essa situação foi em grande medida agravada pela própria dificuldade de implantação das bibliotecas escolares, o que só aconteceu a partir de 1920 quando

\footnotetext{
começaram a surgir com a criação das escolas normais e, mais tarde, dos ginásios estaduais, nesse mesmo período. No início, essas bibliotecas eram destinadas aos estudantes e professores e, posteriormente, bibliotecas infantis foram implantadas nos ginásios para os alunos do ensino primário. Já em 1998, através do Manual Básico da Biblioteca Escolar, o MEC orientava a criação e organização de bibliotecas, sugerindo até o improviso, no caso de ausência de condições físicas e materiais adequados (KOLOKATHIS, 2008, p. 6 , grifo nosso).
}

A denominada prática do professor ou do bibliotecário limitava-se a ações ou atividades isoladas como a recorrente e restrita "contação de histórias", seguida de tarefas 
como reescrita do texto, ilustração da história etc. A ausência de estruturação da prática de promoção da leitura, do ponto de vista da atuação do professor, já foi tema de reflexão e, ainda que a atuação do bibliotecário o esteja sendo agora, convivemos com uma herança do trabalho docente com a leitura também no ambiente da biblioteca e a reproduzimos, em maior ou menor grau, muito em função de negligenciarmos uma prática e a reflexão dessa prática específica e necessária para a biblioteca e para a escola.

Analisando o que acontecia na escola se conclui que

em seu interior existiam tanto práticas possibilitadoras e incentivadoras da leitura,
quanto práticas que dificultavam a aproximação com a leitura. Entretanto, as práticas
de leitura se desenvolviam de forma um pouco aleatória, bastante intuitiva, sem
planejamento rigorosamente definido, revelando um certo "espontaneísmo" que leva
a concluir sobre a importância do professor refletir sobre a própria prática e a
necessidade de que a escola elabore um projeto pedagógico que inclua a leitura com
um eixo de ações previstas e planejadas (SILVA, 1997, p. 189-190).

A própria associação, como sinônimos, do termo "prática" e "atividades", "ações" e/ou "projetos" é indicação clara de que a confusão era de ordem inclusive teórica - de concepção, estruturação e execução do trabalho com a leitura e de organização e definição de objetivos da escola, não só do profissional.

Por outro lado, a discussão sobre as práticas de promoção de leitura, que foi conduzida por docentes pesquisadores das áreas de educação, biblioteconomia e ciência da informação estavam amparadas, conforme nos reporta Silva (1995), em quebrar a passividade tecnicista em que estava fundado o trabalho biblioteconômico buscando orientá-lo ao processo de discussão a respeito da relação entre as práticas biblioteconômicas e os aspectos políticos da socialização do saber. Não tratavam assim, diretamente das práticas em si, mas dos aspectos que poderiam norteá-la.

\section{Práticas de promoção de leitura - Acepções do termo}

A leitura dos trabalhos revelou um total de nove termos distintos para designar as práticas de promoção de leitura: "atividades de leitura", "práticas de leitura”, "ações de leitura", "práticas pedagógicas", "práticas informacionais de leitura", "estratégias de dinamização de leitura", "práticas educativas", "projetos de leitura" e "programa de leitura". Em um mesmo trabalho foi utilizado mais de um termo, porém, com o mesmo sentido. $\mathrm{O}$ GRÁFICO. 5 apresenta os termos encontrados nas referências analisadas. 


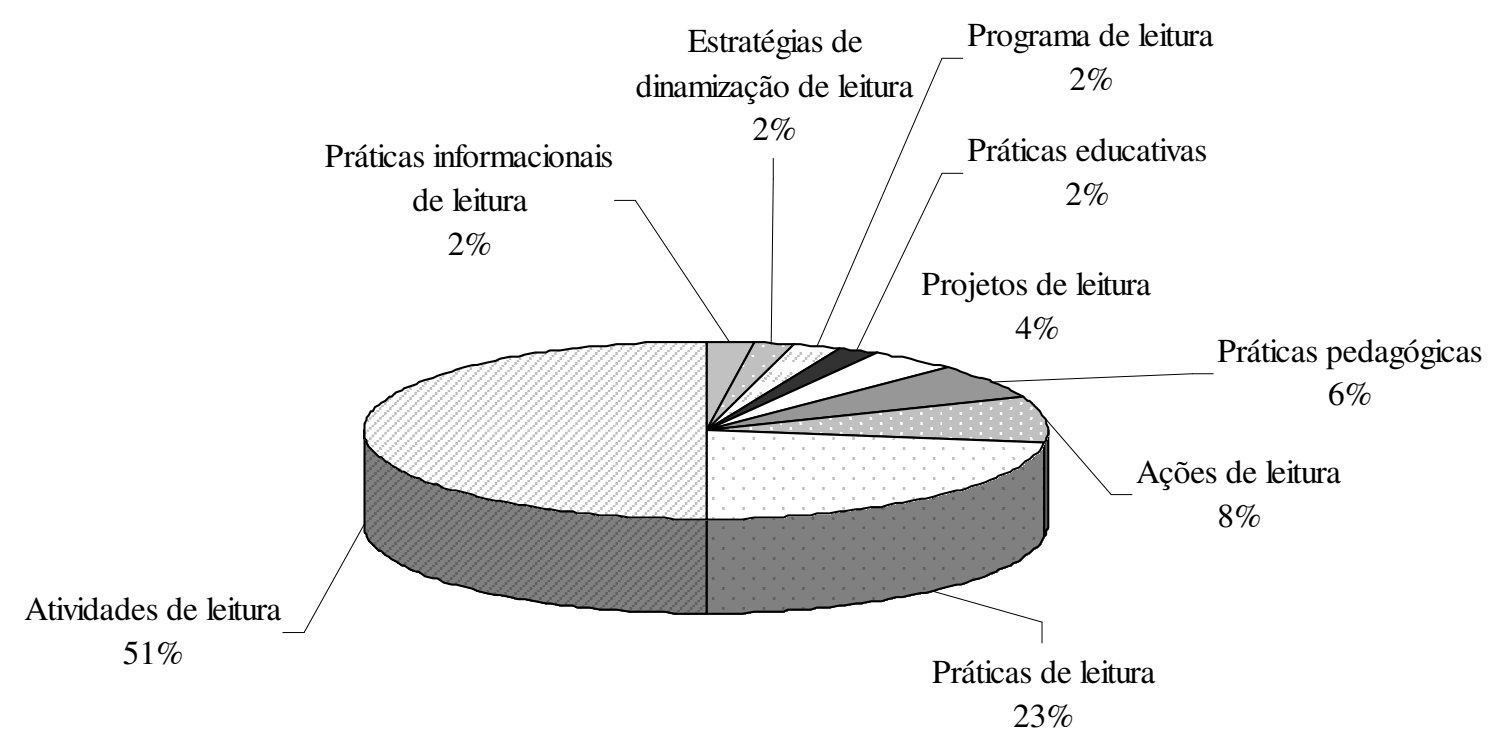

GRÁFICO 5 - Termos utilizados para designar práticas de promoção leitura Fonte: Dados coletados na pesquisa na base LIBES de março a junho/2013

A adoção indiscriminada dos termos para designar o que são as práticas de formação de leitor denota inconsistência e ausência de entendimento acerca do conceito e do próprio funcionamento delas, causando confusão e dispersão.

O termo "atividade de leitura", mais adotado em todas as referências lidas, e seu posterior correspondente "programa de leitura", concentram-se primordialmente no período de 1971 a 2000. A descrição de sua constituição e funcionamento indicam a transposição pura e simples das atividades da sala de aula para a biblioteca ou, quando muito, com uma superficial adaptação "permitida" pelo espaço biblioteca.

A expressão "permitida" é devida a alguns esforços e a partir da própria mudança da concepção de educação no Brasil, aludida no início em Bari e Vergueiro (2008), quando as "atividades de leitura" passaram a ser entendidas e buscadas como distintas daquelas feitas em sala, pois o entendimento sobre o que seria a biblioteca escolar e como ela deveria funcionar, foi igualmente se alterando dentro das escolas e da dinâmica do ensino. Logo, o espaço biblioteca escolar passou a permitir outros arranjos e rearranjos.

Um desses rearranjos deu-se na perspectiva da animação da leitura, que tinha o propósito de dinamizar a própria vivência da leitura no ambiente escolar, especialmente na 
biblioteca, lançando mão de vários recursos, como os teatrais, com o objetivo de ampliar o trabalho da leitura para além dos rígidos processos escolares, que a tratavam unicamente como um meio e não um fim. Perroti (1990) explica que a animação da leitura passou assim a ser uma das estratégias de fazer frente às representações negativas da promoção da leitura comumente adotadas nas escolas.

Foi por esta época, em torno do ano de 1985 que, enfatizada a orientação social do trabalho com a leitura e, o trabalho na biblioteca, entendida agora como espaço de informação e cultura, que aparece pela primeira vez o termo "ação de leitura" e "prática de leitura", $3^{\circ}$ e $2^{\circ}$ termos respectivamente mais adotados nas referências. Mais adiante, precisamente em 1995, e nesta lógica, surge a terminologia "projeto de leitura".

A noção de promoção da leitura e o que se entendia por promover a leitura, dentro da biblioteca escolar, amplia-se do tradicional escopo de atividades de difusão/acesso como suporte para mediar os processos educacionais para a participação dinâmica e ativa na formação e informação dos indivíduos. Foram incorporados assim, conceitos e atividades também de cunho cultural.

Não encontramos distinção quanto ao tipo do profissional realiza as "atividades", "ação" ou "práticas de leitura". O que mudou foi a concepção de ensino, do trabalho com a leitura e, em paralelo, a biblioteca. Não foi encontrada reflexão alguma sobre a particularidade de atuação deste ou daquele profissional, o que pode justificar a inexistência do termo "práticas educativas bibliotecárias", o qual passaremos a propor a seguir.

Uma única referência adotou o termo "práticas educativas". Estava no livro Ezequiel Silva, de 1985 reeditado em 1995 (SILVA, 1995), termo este que entendemos mais exato para conceitualizar a prática que se deseja e ao qual acrescentamos o "bibliotecárias" por refletir que a particularização dos esforços garante um trabalho mais rico e também porque falta uma legitimação histórica, como foi visto, da presença e atuação deste profissional no espaço da biblioteca escolar, principalmente no que diz respeito à promoção da leitura.

Por fim, a análise das acepções/termos também revelou inconsistência quanto aos seus objetivos norteadores. Exemplo disto é que não foi feita distinção clara, em nenhum deles, se o trabalho almejado com a leitura era da ordem da promoção do hábito ou do gosto.

Para Magnani (1989) a passagem da quantidade para a qualidade da leitura (e viceversa) pressupõe um processo de aprendizagem que torna possível aprender a ler e formar o 
gosto. A formação do gosto passa pela retomada das relações, do ponto de vista das possibilidades políticas, entre leitura, literatura e escola, para desestabilizar a dicotomia entre prazer e saber.

Os profissionais, professores ou bibliotecários, afirmavam estarem em busca da promoção da leitura ora pelo hábito, ora pelo gosto, indicando que não há consenso sobre que aspecto da leitura promover o que denota indefinição e/ou incompreensão da leitura a ser trabalhada na escola e na biblioteca escolar.

As acepções "atividades de leitura" e "programa de leitura" estavam comumente associadas ao desenvolvimento do hábito, o que se alterou passado o tempo.

Já os "projetos de leitura", "práticas de leitura" e "ação de leitura" oscilaram entre a promoção do hábito e do gosto, sendo o último o que mais dedicou-se a promoção do gosto da leitura.

O "estratégias de dinamização da leitura" e "práticas informacionais de leitura" não trataram nem de hábito nem de gosto da leitura.

\section{Conclusão}

O levantamento realizado indica que não há, consolidada, uma prática bibliotecária de promoção de leitura e menos ainda uma "prática educativa bibliotecária de formação de leitor".

O termo "práticas educativas bibliotecárias de formação de leitor" é proposto partindose do pressuposto de que é necessária a estruturação formal de uma prática que englobe concepções, ações, procedimentos próprios do profissional bibliotecário e que, portanto, o individualize porque

\footnotetext{
a força e o sucesso de uma profissão são legitimadas pela delimitação clara de seu campo de competência, pela delimitação de um espaço próprio de ação e através de sua interação com outras profissões" (CUNHA; CRIVELLARI, 2004, p. 42).
}

Somadas as particularidades do campo e da atuação profissional, entende-se que o "educativas" pode representar o elemento pedagógico que falta à atuação bibliotecária que, destaca Silva (1995), é condição para que seja significativa e rica, sendo o pedagógico entendido como um 
caminho objetivo, pelo qual se conduz alguém ao conhecimento. [...] até agora, o que se tem feito na biblioteca é indicar, mostrar, dispor, e não conduzir, facilitar o acesso ao conhecimento (BARROS, 1987, p. 13).

Quanto à inclusão do "formação de leitor" em vez de uma genérica e simples "promoção da leitura", tem-se a intenção de revestir o termo de uma intencionalidade política e formativa, próprias do que se espera que seja um trabalho, de fato, educativo.

Isto se deve sim, ao estágio de maturidade da discussão no âmbito da biblioteconomia e da Ciência da informação, no que diz respeito à delimitação da atuação e da função do bibliotecário no contexto escolar, mas também, ao nível de organização e funcionamento do sistema educacional brasileiro que, decisivamente, influi sobre a biblioteca escolar e ao trabalho demandado à ela.

Neste aspecto, acreditamos que a reflexão proposta sobre a "prática educativa bibliotecária de formação de leitor" se justifica e se valoriza na medida em que contribui para situar a discussão desta temática pungente garantindo assim sua evolução teóricometodológica.

\section{Referências}

ALMEIDA JÚNIOR, O. F. Leitura, mediação e apropriação da informação. In: SANTOS, J. P. A leitura como prática pedagógica: na formação do profissional da informação. Rio de Janeiro: Fundação Biblioteca Nacional, 2007. p. 33-46.

BARI, V. A.; VERGUEIRO, W. Biblioteca escolar, leitura e histórias em quadrinhos: uma relação que se consolida. 2008. Disponível em:

$<$ https://ri.ufs.br/bitstream/123456789/336/1/BibliotecaEscolarLeitura.pd>. Acesso em: 02 fev. 2013.

BARROS, M. H. T. C. Presença de elementos pedagógicos nos serviços

biblioteconômicos. Dissertação (Mestrado) - Departamento de Biblioteconomia, Pontifícia Universidade Católica de Campinas, 1987.

BARTHES, R.; COMPAGNON, A. Leitura. In: Enciclopédia Einaudi. Lisboa: Imprensa Nacional/Casa da Moeda, v. 11, p. 184-206, 1987.

CARVALHO, M. C. A formação literária do jovem leitor. CRB 6 Informa. Belo Horizonte, v. 4, n. 1, p. 8-11, 2012.

CARVALHO, M. C.; SOUZA, N. C. R. Letramento literário e mediação na escola: algumas considerações. In: MOURA, M. A. Educação científica e cidadania: abordagens teóricas e metodológicas para a formação de pesquisadores juvenis. Belo Horizonte: UFMG/PROEX, 2012. p. 195 - 204 
CUNHA, M. A. A. Acesso a leitura no Brasil. In: AMORIN, G. (Org.). Retratos da leitura no Brasil. São Paulo: Imprensa Oficial, 2008. p. 49 - 60. Disponível em:

<http://www.prolivro.org.br/ipl/publier4.0/texto.asp?id=1815> Acesso em: 18 dez. 2012.

CUNHA, M. V. CRIVELLARI, H. M. T. O mundo do trabalho na sociedade do conhecimento e os paradoxos das profissões de informação. In: VALENTIM, M. L. P. (Org.). Atuação profissional na área de informação. São Paulo: Polis, 2004. p. 41-54.

GALVÃO, A. M. O.; BATISTA, A. A. G. A leitura na escola primária brasileira. Revista Presença Pedagógica, v. 4, n. 24, nov./dez., 1998.

IPL - Instituto Pró-Livro. Retratos da leitura no Brasil. Resultados da $3^{\text {a }}$ edição da pesquisa Retratos da Leitura no Brasil apresentados no $2^{\circ}$ Seminário Nacional, Brasília, DF, 29 de março de 2012. Disponível em $<$ http://www.prolivro.org.br/ipl/publier4.0/dados/anexos/2834_10.pdf $>$. Acesso em: 20 jun. 2013.

MACEDO, N. D. Leitura e sintonia entre bibliotecário e professor, eis a questão! In: SANTOS, J. P. A leitura como prática pedagógica: na formação do profissional da informação. Rio de Janeiro: Fundação Biblioteca Nacional, 2007. P. 47-64.

MAGNANI, M. R. M. Leitura, literatura e escola: subsídios para uma reflexão sobre a formação do gosto. São Paulo: Martins Fontes, 1989.

KOLOKATHIS, M. L. B. Programa Bibliotecas Escolares: memórias/histórias de uma experiência de incentivo à leitura nas escolas municipais de Campinas - 1993 -2001.

Dissertação (Mestrado em Educação) - Faculdade de Educação, Universidade Estadual de Campinas, 2008.

PERROTI. E. Confinamento cultural, infância e leitura. São Paulo: Summus, 1990.

SILVA, E. T. Leitura na escola e na biblioteca. Campinas: Papirus, 1995.

SILVA, S. A. Práticas e possiblidades de leitura na escola. Dissertação (Mestrado em Educação) - Faculdade de Educação, Universidade Federal de Minas Gerais, 1997.

STERN, C. Information literacy unplugged: teaching information literacy without technology. White paper prepared for UNESCO, the US NCLIS and National Forum for Information Literacy. Disponível em: <http://www.nclis.gov/libinter/>. Acesso em: 20 jun. 2013.

YUNES, E. Dados para uma história da leitura e da escrita. In: (Org.). Pensar a leitura: complexidade. São Paulo: Loyola, 2002, p. 52 - 59. 